\title{
THE EFFECT OF NOTCH DEPTH ON CTOD VALUES IN FRACTURE TESTS OF STRUCTURAL STEEL ELEMENTS
}

\author{
Jakub Kowalski \\ Janusz Kozak \\ Gdańsk University of Technology, Poland
}

\begin{abstract}
In elements of steel structures working at low temperatures, there is a risk of appearance of brittle fracture. This risk is reduced through the use of certified materials having guaranteed strength at a given temperature. A method which is most frequently used to determine brittle fracture toughness is the Charpy impact test, preformed for a given temperature. For offshore structures intended to work in the arctic climate, the certifying institutions more and more often require Crack Tip Opening Displacement (CTOD) tests instead of conventional impact tests, especially for steel and welded joints of more than $40 \mathrm{~mm}$ in thickness in the case of high-strength steel, and more than $50 \mathrm{~mm}$ for the remaining steels. The geometry of specimens and the test procedure are standardised; however, these standards provide some margin for specimen notch depth. The paper analyses the effect of notch depth difference, within the range permitted by the standards, on the recorded CTOD values of a given material. The analysis was performed via numerical modelling of destruction of specimens with different notch geometries and further verification of the obtained numerical results in laboratory tests. The calculations were carried out at the Academic Computer Centre in Gdansk.
\end{abstract}

Keywords: brittle fracture; CTOD; numerical modelling; laboratory tests

\section{INTRODUCTION}

The progressive development of civilisation brings forth the need for energy, being the source of functioning of societies. The exploitation of available sources of fossil fuels has led to the depletion of inland resources, in particular crude oil being the basic energy raw material, and shifted their exploration and extraction to offshore areas of continental shelfs in various regions of our globe. However, the easiest accessible resources in those areas were already highly depleted at the turn of the century and the extraction has moved towards arears which are less friendly to people and extracting installations - including polar areas. After founding, the extracting installations work throughout the year irrespective of weather conditions, therefore the material used for their manufacturing shall meet difficult operating conditions, including changing loads and a wide range of temperature changes, in which they are expected to preserve their mechanical properties.

Foer these reasons, determining mechanical properties of materials in changing (low) temperatures are becoming more and more important, the more so that possible failure of an oil production platform in the Arctic brings threat for both people working on it, and the environment at the place of its foundation.

\section{THE PROBLEM OF BRITTLE FRACTURE OF STRUCTURAL STEEL ELEMENTS}

The abovementioned unfriendly environment, along with inability to perform periodical complete inspections of the structure (which is done with respect to ships) forces the designers to include the issue of structure strength in the presence of developing cracks to the strength analysis. These cracks, in the form of microdefects, are always present in the welded steel structure, therefore analysing the above issue is necessary for structures working in changing load conditions. The cracking process in the structure can take a different course: from slow development of fatigue crack to rapid brittle damage. The latter form of cracking is especially dangerous for the structure. It starts suddenly and is rapid, moreover the energy for its initiation is much lower than that 
needed in plastic destruction. The process of brittle cracking develops with the speed close to the acoustic velocity and goes along the cleavage planes or on grain boundaries. The type of the cracking is decided by a large number of factors, among which the temperature plays a non-trivial role [1].

A group of different tests used to determine mechanical properties of materials or welded joints includes the Charpy impact test, which determines their brittle fracture toughness. The procedure of this test is standardised. At present, it is usually performed in accordance with the standard PN-EN ISO 148-1:2010 or ASTM E23-12c [2], [3]. The result of the test is the amount of work needed to facture the specimen with notch at the temperature relevant for given steel category. The number of test specimens, the places from which they are taken and their orientation, as well as the test fulfilment criteria, are selected depending on the type of tested object (material or welded joint). For instance, for higher-strength ship steel, $\mathrm{R}_{\mathrm{p} 02}=355 \mathrm{MPa}$, and category $\mathrm{D}$ (test temperature: $-20^{\circ} \mathrm{C}$ ), the minimal required impact toughness is equal to $34 \mathrm{~J}$ in the rolling direction and $24 \mathrm{~J}$ in the transverse direction for steel sheets of up to $50 \mathrm{~mm}$ in thickness, while for sheets of thickness ranging within $70-100 \mathrm{~mm}$ the required impact toughness will be as high as $41 \mathrm{~J}$ in the rolling direction and $27 \mathrm{~J}$ in the transverse direction [4]. The relation between the test temperature and the fracture mechanism for steel is only indicated by the fracture energy described by the so-called brittle state transition curve - Fig. 1.

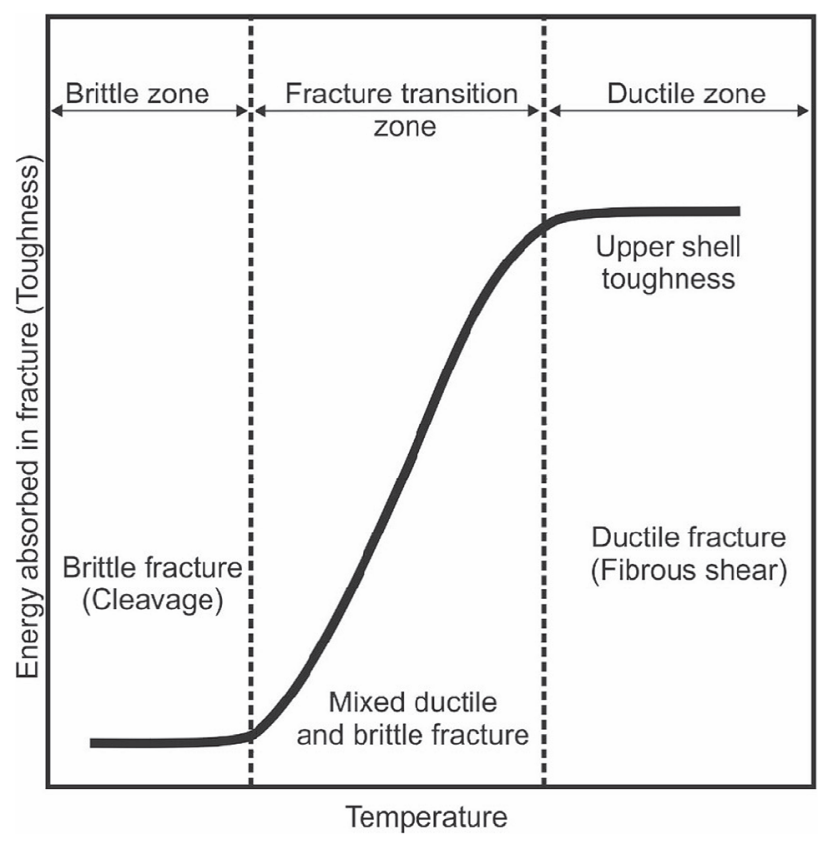

Fig. 1. Typical transition curve from ductile state to brittle state for constructional steel [10]

For some reasons, testing material ductility with the Charpy test may be insufficient. This is a quantitative test and its result does not say anything about the nature of cracking. Another source of ambiguity of the Charpy test is that its results highly depend on the notch geometry in the test specimen. However, these notches are cut mechanically, and their geometry depends on the shape of the used cutter, which changes with time and produces different notch shapes.

For the above reasons, more perfect methods to assess material ductility are wanted. Basing the methodology of sampling on the fatigue mechanics has made it possible to obtain qualitative, and not only quantitative results.

The group of fatigue mechanics-based material ductility tests includes: determining the critical stress intensity factor for the I-th form of cracking - $\mathrm{K}_{\mathrm{IC}}$, as well as determining the critical value of the integral $J$ and/or the value of critical Crack Tip Opening Displacement (CTOD) [5]. At present, the regulations and requirements applicable in the shipbuilding industry are limited to CTOD testing, however the requirements of the Engineering Equipment and Materials Users Association (EEMUA) [6] name also the integral J as a criterion.

\section{CTOD CRITERION AS THE MEASURE OF BRITTLE FRACTURE TOUGHNESS OF STEEL}

CTOD is the criterion introduced by A.A. Wells in 1963. It can be considered as the deformation-related measure of material fracture toughness and reaching its critical value is a signal of material cracking [7]. There are relations between the CTOD value and other quantities, such as integral J, factor $\mathrm{K}_{\mathrm{I}}$, or impact strength, which characterise material's ability to crack [8].

The essence of the CTOD test consists in breaking a specimen representing full thickness of the material subjected to verification. The specimen has a preliminary, mechanically cut notch, which then develops under the action of fatigue load to such a large size than the effects of mechanical treatment stay far from the front of the fatigue notch and the shape of the notch front is repeatable for each specimen. To check this repeatability, the result of the test is only accepted after the specimen is fully fractured and the proportion of the fatigue fracture front is finally verified. Fig. 2 shows the specimen $\mathrm{Bx} 2 \mathrm{~B}$, acc. to [9], [10].
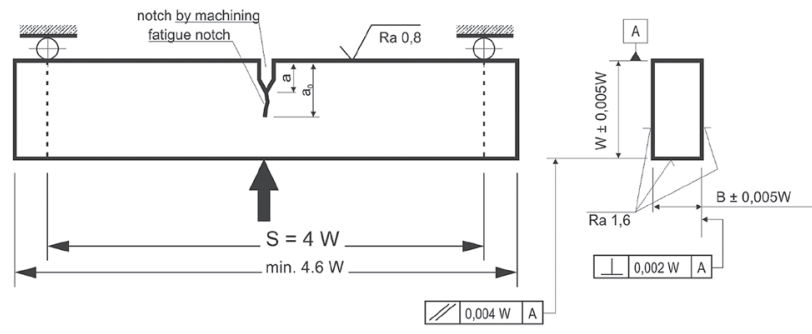

Fig. 2. Bx2B specimen bent at three points for CTOD test, after [10]

The measure of material's brittle fracture toughness is the value of opening at the notch bottom, determined by measuring the notch opening at the upper notch edge (CMOD - Crack Measured Opening Displacement) - Fig. 3. 


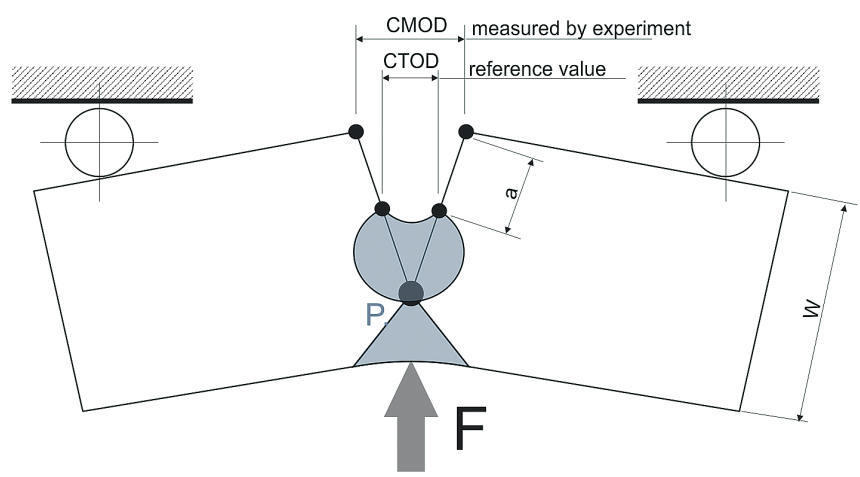

Fig. 3. Opening at notch bottom vs. notch opening measurement [11]

For some offshore structures, the classification societies, such as DNVGL or Lloyd's Register of Shipping for instance [12], and in particular the standards NORSOK [13] and EEMUA [6], do not stop at checking the material impact value and more and more frequently require also CTOD testing. The structures for which the above requirements are imposed include thick-plating structures (with plate thickness over $50 \mathrm{~mm}$ ), tension leg platforms (of both extraction and hotel type), and offshore wind power plants (for instance of monopile type structure). Below given are the standards for CTOD tests of welded joints in offshore structures to which the abovementioned regulations refer.

As far as the CTOD test is concerned, these regulations refer to three standards: [9], [10] and [14], which require performing the test on specimens which are bent at three points. The proportions of specimen cross section dimensions are $\mathrm{Bx} 2 \mathrm{~B}$, or alternatively $\mathrm{Bx} \mathrm{B}$, where $\mathrm{B}$ is equal to the thickness of the tested sheet. These regulations simultaneously define the limiting permissible value of CTOD - Tab. 1 .

A drawback of the geometry defined in the above way, in which all dimensions of the specimen are related to the thickness of the sheet subjected to testing, is the mass of the tested element. For instance, a specimen taken from the sheet of $100 \mathrm{~mm}$ in thickness has the dimensions: $\mathrm{B}=100$ $\mathrm{mm}, 2 \mathrm{xB}=200 \mathrm{~mm}$, and the total length equal to $920 \mathrm{~mm}$. The approximate mass of this specimen is $147 \mathrm{~kg}$ - Fig. 4 . Preparing and testing the specimen of such a large size and mass is technically difficult and there are few laboratories in Europe which have technical potential for performing such tests.

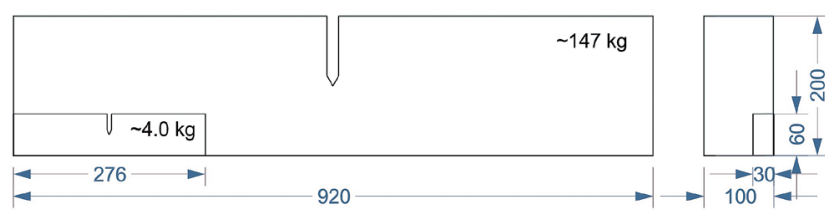

Fig. 4. Comparing mass and dimensions of specimens made of sheets of 30 and $100 \mathrm{~mm}$ in thickness

The standards [9] and [10] define the permissible range of notch depth to specimen height ratio, $\mathrm{a}_{0} / \mathrm{W}$, as $0,45-0,55$ [9] or $0,45-0,70$ [10]. As can be seen, there is some arbitrariness in here. On the other hand, if the criterial CTOD value is defined unambiguously (Tab. 1), then a question can be raised whether changing the $a_{0} / W$ value of does not really affect the CTOD value.

The above problem is analysed in two ways in the paper: firstly, by numerical modelling of the test specimen fracture process and then, by experimental verification of the obtained numerical results in laboratory tests.

\section{NUMERICAL MODEL OF SPECIMEN DESTRUCTION CTOD}

When defining the material destruction method to be used in the numerical model, three behaviour areas were named in the destruction process: the (linear) elastic behaviour area, the area of material ductility with consolidation and, finally, the area of material degradation until destruction [15].

A schematic diagram of the destruction mechanism defined in the above way is shown in Fig. 5.

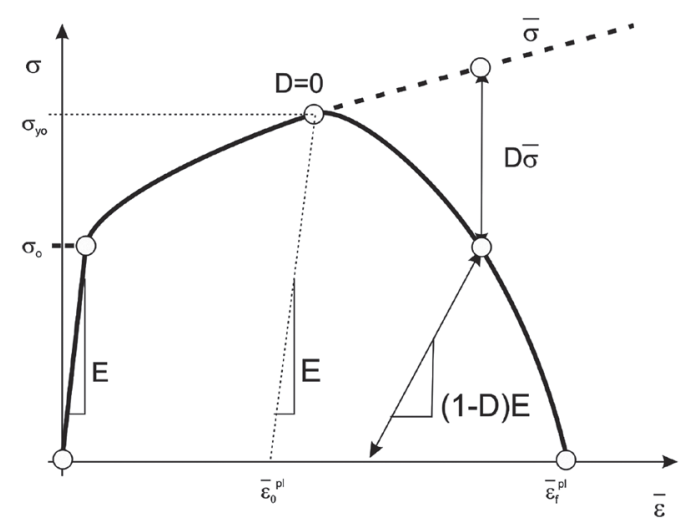

Fig. 5. Schematic diagram of material deformation and degradation [15]

Tab. 1. Selected requirements for CTOD test and criterial values

\begin{tabular}{|c|c|c|c|c|}
\hline Name & $\begin{array}{l}\text { Standards according to which the } \\
\text { test is to be performed }\end{array}$ & $\begin{array}{l}\text { Required CTOD } \\
\text { value }[\mathrm{mm}]\end{array}$ & Specimens & Additional requirements \\
\hline $\begin{array}{l}\text { DNV GL C201 / } \\
\text { C401[4] }\end{array}$ & $\begin{array}{l}\text { ISO } 12135: 2002 \text { and } \\
\text { ISO 5653:2010, another known } \\
\text { standard }[10]\end{array}$ & 0,15 & $\begin{array}{l}\text { Bent, recommended Bx2B, } \\
\text { acceptable B x B }\end{array}$ & $\begin{array}{l}\text { Specimen shall comply with } \\
\text { all standard's requirements }\end{array}$ \\
\hline EEMUA 158 & ISO 15653:2010 [14] & $\begin{array}{l}\text { Not defined - designer's } \\
\text { decision }\end{array}$ & $\begin{array}{l}\text { Bent, recommended Bx2B, } \\
\text { acceptable B x B }\end{array}$ & $\begin{array}{l}\text { Test shall be performed } \\
\text { within } 21 \text { days after } \\
\text { specimen plate welding }\end{array}$ \\
\hline NORSOK M101 & BS $7448 \mathrm{p} 1$ and p2 [9] & $\begin{array}{c}\text { Not defined - designer's } \\
\text { decision }\end{array}$ & Bent Bx2B & - \\
\hline
\end{tabular}


where:

$\mathrm{D}$ - destruction degree, $(\mathrm{D}=0$ initiation of degradation process, $\mathrm{D}=1$ - fully destructed material)

$\sigma$ - stress, $\varepsilon$ - strain

$\bar{\varepsilon}_{0}^{p l}$ - plastic deformation reduced for the beginning of the degradation process

$\bar{\varepsilon}_{f}^{p l}$ - plastic deformation reduced for the moment of breaking

E - Young's modulus

$\bar{\sigma}-$ reduced stress

$\sigma_{0}-$ yield point

$\sigma_{\mathrm{y} 0}-$ ultimate strength limit

In the process of numerical modelling of CTOD specimen, a parametrised model was worked out in such a way as to provide opportunities for analysing specimens of different material thickness. Real values of the parametrised variables are given in Table 2, with nomenclature defined in Fig. 6.

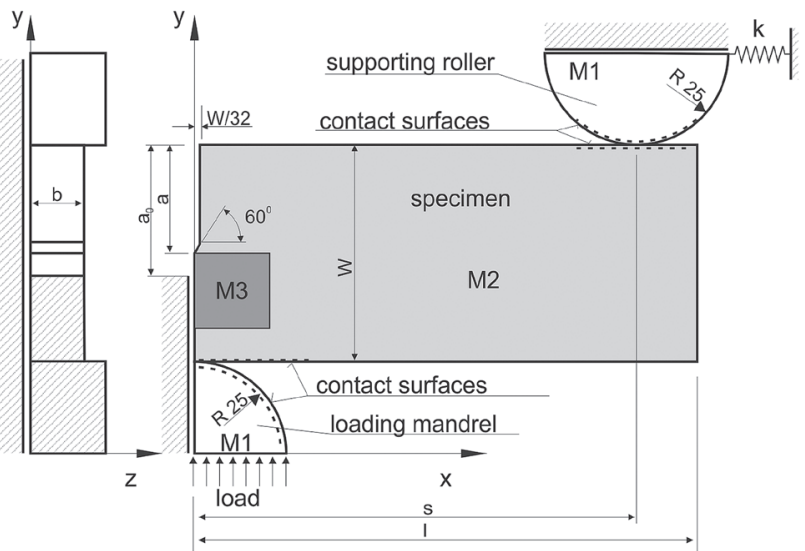

Fig. 6. Parametric model of specimen geometry with material areas, boundary conditions, and method of loading
The effect of the parameter a/W was analysed for steel NV E36 DNV PT.2 CH.2 SEC.1:2016, the mechanical properties of which are collated in Tab. 3 and chemical composition in Tab. 4. Definitions of symbols used in the table:

1) L - longitudinal axis of the specimen coincides with the main rolling direction

2) $\mathrm{T}$ - longitudinal axis of the specimen perpendicular to the main rolling direction

3) total extensometric strain given for the $50 \mathrm{~mm}$ basis, according to [PN-EN ISO 6892-1]

Three different material characteristics, marked in Fig. 6, were used in the model:

- linear elastic characteristic - M1

- fully plastic characteristic - M2

- fully plastic characteristic with destruction - M3

Material data for individual models are given below:

- Model M1:

- Young's modulus $\mathrm{E}=2,06^{\star} 10^{8}[\mathrm{MPa}]$

- Poisson's ratio $v=0,3[-]$

- Model M2:

- Young's modulus $\mathrm{E}=2,06^{\star} 10^{5}[\mathrm{MPa}]$

- Poisson's ratio $v=0,3[-]$

- Plastic characteristic - determined from the tensile test - see Fig. 7

- Model M3:

- Young’s modulus $\mathrm{E}=2,06^{\star} 10^{5} \mathrm{MPa}$

- Poisson's ratio $v=0,3[-]$

- Plastic characteristic - as in model M2

Tab. 2. Dimensions of individual FEM models

\begin{tabular}{|c|c|c|c|c|c|c|}
\hline Name of model & $\mathrm{b}[\mathrm{mm}]$ & $\mathrm{w}[\mathrm{mm}]$ & $\mathrm{s}[\mathrm{mm}]$ & $1[\mathrm{~mm}]$ & $\mathrm{a} 0[\mathrm{~mm}]$ & $\mathrm{a} 0 / \mathrm{w}[-]$ \\
\hline MES B50 a0/W = 0,50 & 25,0 & 100,0 & 200,0 & 230,0 & 50,0 & 0,50 \\
\hline MES B50 a0/W = 0,55 & 25,0 & 100,0 & 200,0 & 230,0 & 55,0 & 0,55 \\
\hline MES B50 a0/W = 0,60 & 25,0 & 100,0 & 200,0 & 230,0 & 60,0 & 0,60 \\
\hline
\end{tabular}

Tab. 3. Mechanical properties of steel used for tests

\begin{tabular}{|c|c|c|c|c|c|c|}
\hline \multirow{2}{*}{ Name of model } & \multirow{2}{*}{$\begin{array}{c}\text { Minimal yield } \\
\text { point } \mathrm{R}_{\mathrm{eH}}[\mathrm{MPa}]\end{array}$} & \multirow{2}{*}{$\begin{array}{c}\text { Minimal } \\
\text { ultimate strength } \\
\text { limit } \mathrm{R}_{\mathrm{m}}[\mathrm{MPa}]\end{array}$} & \multirow{2}{*}{$\begin{array}{c}\text { Minimal strain } \\
\mathrm{A}_{5}[\%]\end{array}$} & \multicolumn{3}{|c|}{$\begin{array}{l}\text { Fracture work, average of three specimens [J], } \\
\text { for sheets of } 50-70 \mathrm{~mm} \text { in thickness }\end{array}$} \\
\hline & & & & $\begin{array}{c}\text { Sampling } \\
\text { temperature }\left[{ }^{\circ} \mathrm{C}\right]\end{array}$ & $\mathrm{L}^{1}$ & $\mathrm{~T}^{2}$ \\
\hline $\begin{array}{c}\text { Requirements } \\
\text { [DNV GL metallic materials] }\end{array}$ & 355 & $490-560$ & 21 & -40 & $\geq 41$ & $\geq 27$ \\
\hline $\begin{array}{l}\text { Material certification } \\
\text { [material certification] }\end{array}$ & 389 & 549 & $27^{3}$ & -40 & 182 & No data \\
\hline Own tests & 398 & 537 & $29^{3}$ & -40 & & \\
\hline
\end{tabular}

Tab. 4. Certification based chemical composition of the tested material

\begin{tabular}{|c|c|c|c|c|c|c|c|c|c|c|c|c|c|c|c|c|c|c|c|c|c|c|}
\hline $\mathrm{C}$ & $\mathrm{Si}$ & $\mathrm{Mn}$ & $\mathrm{P}$ & $\mathrm{S}$ & $\mathrm{Al}$ & $\mathrm{Nb}$ & $\mathrm{V}$ & $\mathrm{Ti}$ & $\mathrm{Cu}$ & $\mathrm{Cr}$ & $\mathrm{Ni}$ & $\mathrm{Mo}$ & $\mathrm{Ca}$ & $\mathrm{Ceq}$ \\
\hline 0,161 & 0,46 & 1,50 & 0,012 & 0,002 & 0,031 & 0,042 & 0,052 & 0,005 & 0,016 & 0,05 & 0,04 & 0,006 & 0,002 & 0,44 \\
\hline
\end{tabular}




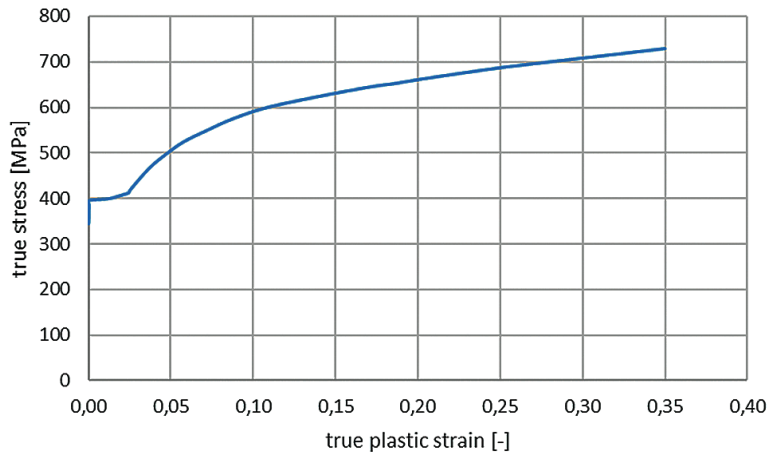

Fig. 7. Plastic characteristic of material used in FEM calculations

When constructing the finite element grid, for each material zone the type of element which best reflects the specificity of this zone was applied. Parameters characterising the finite element in each zone are given in Tab. 5.

Tab. 5. Types of finite elements in the FEM model

\begin{tabular}{|c|c|c|}
\hline Zone & $\begin{array}{c}\text { Type of element, acc. } \\
\text { to }[15]\end{array}$ & Size of element $[\mathrm{mm}]$ \\
\hline M1 & C3D8R & 3,5 \\
\hline M2 & C3D4 & 10,0 \\
\hline M3 & C3D8R & 0,5 \\
\hline
\end{tabular}

Fixed element sizes were used in each FEM model.

Along with the specimen, the support and loading elements were also modelled to preserve the instrumentation action conditions. Constant tension of the spring which maintained constant distance between the supports was assumed equal to $\mathrm{k}=500 \mathrm{~N} / \mathrm{mm}$, based on calibrations performed during the tests. The load was applied by forcing the motion of the bending mandrel along the global y-axis.

The model of finite element grid is shown in Fig. 8.

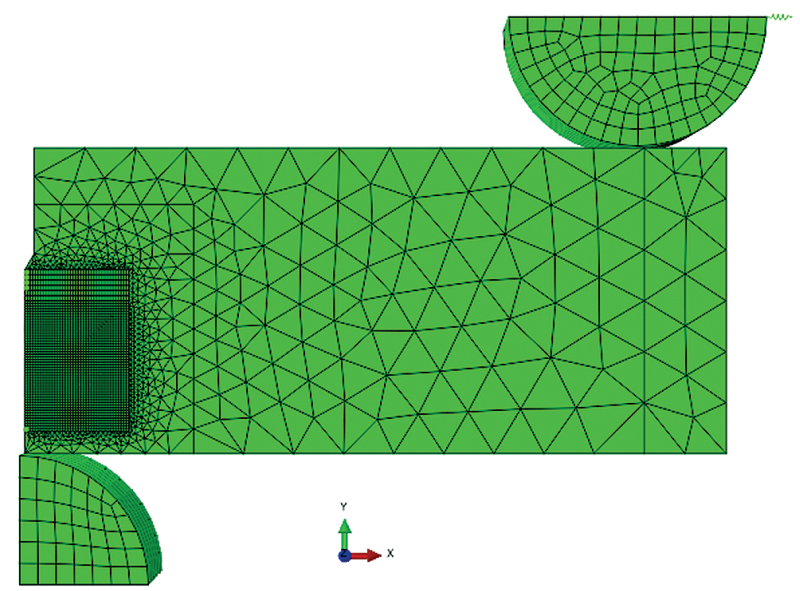

Fig. 8. Finite element grid for MES B30 series model

\section{VALIDATION OF RESULTS THROUGH TESTING THE SPECIMEN BENT AT THREE POINTS}

To check the correctness of the results obtained using the numerical model and, in particular, the adopted material model, CTOD test were performed in accordance with the standard BS7448-1:1991 [9] for specimens of the same geometry and material characteristics as those used in the numerical model. The specimen and the rig used for these tests are shown in Fig. 9.

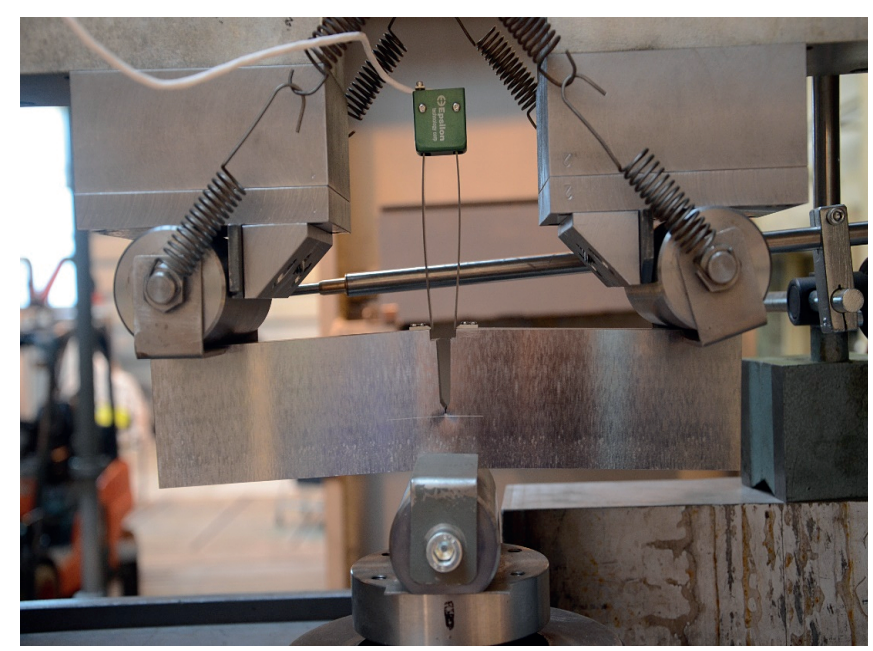

Fig. 9. Real test specimen during laboratory test

Fig. 10 compares the load-CTOD curves determined based on the numerical analysis with those recorded in laboratory tests for six specimens, labelled 1 through 6. Good compatibility of these results can be observed, which testifies to the correctness of the modelling process and, in particular, the applied material model.

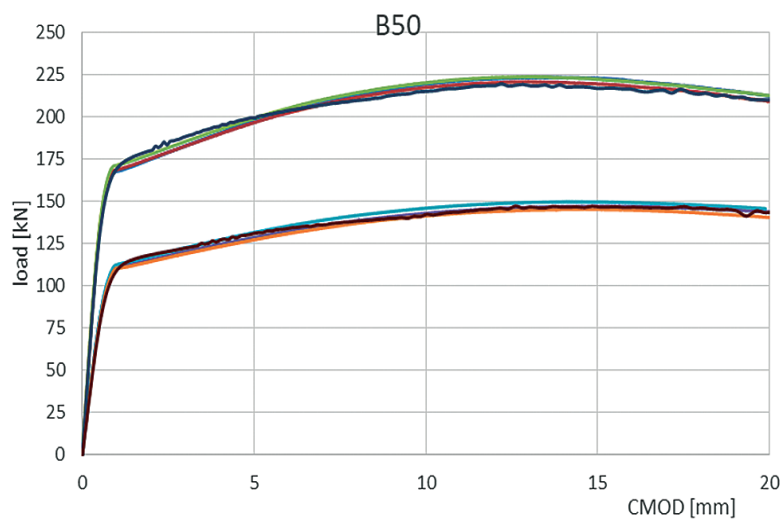

$-1-2-3-4-5-6-\mathrm{FEM} \mathrm{a0} / \mathrm{W}=0.5-\mathrm{FEM} \mathrm{a0} / \mathrm{W}=0.6$

Fig. 10 Comparing load-CTOD characteristics obtained from numerical analysis and laboratory tests

In Fig. 10, the curves labelled 1 through 6 represent experimental test results, while those marked FEM were obtained numerically. 
Fig. 11 presents CTOD values obtained both from the numerical model and experimental tests as a function of the $\mathrm{a}_{0} / \mathrm{W}$ ratio.

B50

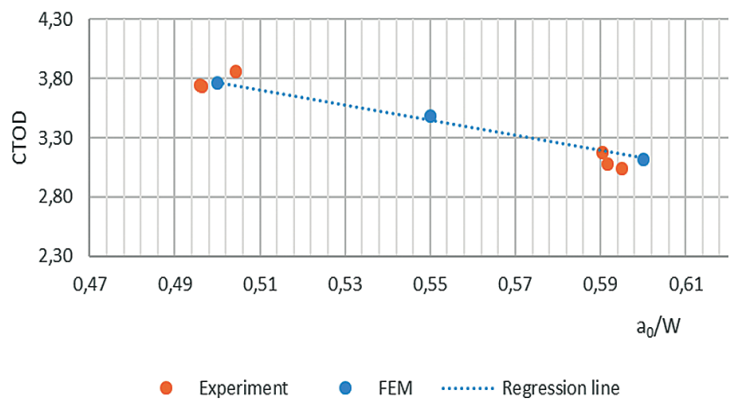

Fig. 11. CTOD as function of ao/W, based on results of numerical analysis and laboratory tests

In Fig. 11 we can clearly see the decrease of the Crack Tip Opening Displacement (CTOD) with the increasing $\mathrm{a}_{0} / \mathrm{W}$ ratio. Moreover, the sensibility of CTOD to this change can be assessed as high.

\section{SUMMARY AND CONCLUSIONS}

In the paper, the thesis of using CTOD as unambiguous measure of brittle fracture toughness of steel is verified.

The applied numerical model was validated through laboratory tests.

The obtained results confirm the applicability of the CTOD test for determining ductility of steel.

The obtained results suggest that care should be taken when comparing CTOD values obtained for specimens, the geometry of which meets requirements of relevant standards but differs by a $0 / \mathrm{W}$ ratio. This is important due to the fact that even small changes of this ratio affect considerably the critical tip notch opening displacement CTOD.

The presented results of numerical calculations reveal the correctness of the adopted material model and conditions describing the destruction process. Nevertheless, if possible, the obtained numerical results have to be subjected to laboratory verification, especially for elements with relatively large thickness, due to complex stress distribution in the destruction area.

\section{REFERENCES}

1. S. Kocańda and J. Szala, Fundamentals of fatigue calculations (in Polish), Warsaw: Wydawnictwo Naukowe PWN, 1997.

2. ASTM, E23 - 16b Standard Test Methods for Notched Bar Impact Testing of Metallic Materials, West Conshohocken (PA): ASTM International, 2016.
3. Polish Committee for Standardisation, PN-EN ISO 148-1:2017-02 Metals - Charpy impact test - Part 1: Test method (in Polish), Warsaw: Polish Committee for Standardisation, 2017.

4. Polish Register of Shipping, Rules for the Classification and Construction of Sea-going Ships, Part IX - Materials and Welding (in Polish), Gdansk: Polish Register of Shipping, 2017.

5. J. R. Rice i D. M. Tracey, "On the ductile enlargement of voids in triaxial stress fields," in J. Mech. Phys. Solids, 17, 1969.

6. EEMUA, Publication 158 Construction Specification for Fixed Offshore Structures In The North Sea, Londyn: The Engineering Equipment And Materials Users' Association, 2014.

7. G. Sih, "Methods of analysis and solutions of crack problems, Vol1.," Noordhoff Int. Publishing, Leyden, ISBN 9001798608., 1973.

8. W. T. Bao Y., "A Comparative Study on Various Ductile Crack Formation Criteria," in Transactions of the ASME, Vol. 126, 2004.

9. British Standard, BS 7448-1:1991 - Fracture mechanics toughness tests. Method for determination of KIc, critical CTOD and critical J values of metallic materials, London: BSI, 1991.

10. ISO, ISO 12135 Metallic materials - Unified method of test for the determination of quasi-static fracture toughness, Geneva: Polish Committee for Standardisation, 2002.

11. A. Neimitz, Fracture Mechanics (in Polish), Warsaw: Wydawnictwo Nakowe PWN, 1998.

12. British Standard, BS 7910:2005 Guide to methods for assessing the acceptability of flaws in metallic structures, Londyn: BSI, 2005.

13. NORSOK STANDARD, M-101, Structural steel fabrication, Lysaker: Standards Norway, 2011.

14. Polish Committee for Standardisation, PN-EN ISO 15653:2010 Metallic materials - Test method to determine quasi-static brittle fracture toughness of welds (in Polish), Warsaw: Polish Committee for Standardisation, 2010.

15. Dassault Systèmes, Abaqus 6.14 Documentation, Providence, RI: Dassault Systèmes, 2014. 


\section{CONTACT WITH THE AUTHOR}

\section{Jakub Kowalski}

e-mail:jakub.kowalski@pg.edu.pl

Janusz Kozak

e-mail:kozak@pg.gda.pl

Gdansk University of Technology

Faculty of Ocean Engineering and Ship Technology

Narutowicza 11/12, 80-233 Gdansk

Poland 